\title{
Highest Grade Pancreatic Intraepithelial Neoplasia
}

National Cancer Institute

\section{Source}

National Cancer Institute. Highest Grade Pancreatic Intraepithelial Neoplasia. NCI

Thesaurus. Code C159309.

A directive to choose the highest grade of pancreatin intraepithelial neoplasia. 